\title{
Characteristics of deceased and quality of death certificates for cases subjected to Indonesia's management of the dead protocol for bodies with COVID-19
}

\author{
Putri Dianita Ika Meilia ${ }^{1}$ (D) Citra Manela ${ }^{2} \cdot$ Yudy $^{3} \cdot$ Retno Sawitri $^{4} \cdot$ Yoni F. Syukriani $^{5} \cdot$ Berlian I. Fitrasanti $^{5}$. \\ Annisa A. Muthaher ${ }^{6} \cdot$ Kanina Sista $^{7} \cdot$ Evi Untoro $^{8} \cdot$ Sumy H. Purwanti ${ }^{9} \cdot$ M. Zaenuri S. Hidayat ${ }^{10}$
}

Accepted: 5 December 2021 / Published online: 7 February 2022

(c) The Author(s), under exclusive licence to Springer Science+Business Media, LLC, part of Springer Nature 2022

\begin{abstract}
The COVID-19 pandemic has significantly impacted many aspects of life, including death care. International and national protocols have been implemented for the management of the dead. This study aims to determine the characteristics of decedents managed according to COVID-19 protocols in Indonesia and the quality of their death certificates. This study uses a descriptive, cross-sectional design. Secondary data of deaths with COVID-19 were taken from hospital death registries, medical records, and death certificates. Data were collected from nine referral hospitals and one funeral home in 6 cities in Indonesia. The majority of the decedents were male, Muslim, with a median age of 57. Most were treated in non-intensive isolation wards, and almost half had known comorbidities. Many were still awaiting the result of their confirmative PCR at the time of death. Almost all were managed compliant with the standard protocol, and most were buried in COVID-only cemeteries. There were still deficiencies in the completeness and accuracy of the death certificates. "COVID-19" was mentioned as a cause of death in only about half of the cases, with a wide variety of terms and spelling. Management of the dead protocols for bodies with COVID-19 can generally be implemented in Indonesia. The quality of the death certificates should, however, be continuously improved.
\end{abstract}

Keywords COVID-19 death · Management of dead bodies $\cdot$ Death certification $\cdot$ Multiple causes of death

\section{Introduction}

The disease caused by the SARS-CoV-2 virus (coronavirus disease 2019/COVID-19) has spread almost worldwide since December 2019. The effect of the COVID-19 pandemic is felt not only in the health sector but also in many

Putri Dianita Ika Meilia antalya22ftf@gmail.com

1 Forensic Medicine and Mortuary Department, Persahabatan General Hospital, Jakarta, Indonesia

2 Faculty of Medicine, Universitas Andalas-Dr. M. Djamil General Hospital, Padang, Indonesia

3 Faculty of Medicine, Universitas Indonesia-Dr. Cipto Mangunkusumo General Hospital, Jakarta, Indonesia

4 Forensic and Mortuary Department, Fatmawati General Hospital, Jakarta, Indonesia

5 Faculty of Medicine, Universitas Padjadjaran-Dr. Hasan Sadikin General Hospital, Bandung, Indonesia other aspects of life. One sector that has been quite heavily affected is the post-mortem handling of dead bodies infected, or suspected to be infected, with COVID-19. In addition to preventing possible infection transmission from the dead bodies, post-mortem management must also consider the social and religious needs of the grieving relatives [1-3].

6 Faculty of Medicine, Universitas Hasanuddin, Makassar, Indonesia

7 Forensic Medicine and Mortuary Department, Dr. Soeradji Tirtonegoro General Hospital, Klaten, Indonesia

8 Faculty of Medicine, Universitas Trisakti, Jakarta, Indonesia

9 Central Java Regional Police Medical and Health Division, Semarang, Indonesia

10 Faculty of Medicine, Universitas Jenderal Soedirman, Purwokerto, Indonesia 
To help deal with the COVID-19 outbreak, special deadbody management protocols are carried out. There are various guidelines for managing the dead body of COVID-19 patients issued by international and national organizations [4-6]. These guidelines guide the general management of dead bodies with COVID-19, from the moment of death to the funeral, to ensure the safety of everyone involved in the process. Several guidelines about medical certification of death and cause of death are also available. Formally, Indonesia uses the international form of medical certificate of cause of death [7]. In cases with COVID-19 infection, several factors must be considered in the certification of the cause of death, including the clinical presentation and epidemiological history. The term "COVID-19" must be included in the death certificate for all cases where COVID-19 is a disease that caused, or is considered to have caused, or contributed to, death $[8,9]$.

The number of COVID-19 cases continues to grow. As of 22nd December 2020, at the time of writing, based on data from the website https://covid19.go.id/, there were 671,778 confirmed positive cases of COVID-19 in Indonesia, with a death toll of 20,085 cases. Despite the growing number of cases and fatalities, the implementation of the abovementioned guidelines, both for the management of the dead and certifying causes of death in Indonesia, is unknown. This study aims to determine the number and characteristics of bodies managed according to the guidelines for managing dead bodies with COVID-19 and the quality of their death certificates in various regions in Indonesia.

\section{Methods}

This study uses a quantitative cross-sectional design. Data were collected from several hospitals which were designated as "COVID-19 referral hospitals" by the government, either since the beginning of the pandemic or during the subsequent months. The research was conducted from April 23 to December 21, 2020.

\section{Population and sample}

For surveillance purposes, a "COVID-19 death" is defined as "any death of a person with probable/confirmed COVID-19" [6]. However, for this study, we wanted to focus on the management of dead bodies according to special COVID-19 protocols by forensic medical specialists in Indonesia. Sometimes a more prudent approach was chosen, and some decedents were managed according to the COVID-19 protocols even if they did not strictly fall into the "probable/confirmed" category (i.e., "suspected" COVID-19 infection). Thus, the population of this study was all dead bodies that were managed according to protocols for the management of dead bodies with COVID-19 in Indonesia. The study sample was taken using the following criteria: cases were included if they were managed according to the protocol for handling dead bodies with COVID-19 in institutions with a forensic medicine and medicolegal specialist. Cases were excluded if their death certificate and medical record cannot be accessed.

\section{Sample size}

Because this study aimed to obtain an overview of managing the dead, all cases from the accessible population that met the sample criteria were included [10].

\section{Data collection}

Data were collected from secondary data sources (death certificates, medical records, and death registries) using a Google Sheet form. The variables in this study were:

- Characteristics of the decedent: age, sex, religion, in-patient status, type of in-patient ward, COVID-19 infection status at the time of death, comorbidity, compliance with COVID-19 management of the dead protocol, type of funeral.

- Quality of the death certificate: completeness of each input variable in the death certificate, description of the direct, intermediate, and underlying causes of death, conditions contributing to, but not related to, the cause of death, time interval from the start of the cause of death until death, and the relevant International Classification of Diseases 10th revision (ICD-10) codes.

\section{Data analysis and presentation}

Data were analyzed using SPSS ${ }^{\circledR}$ version 21.0. Categorical data are presented in figures and tables as frequencies and proportions. In contrast, numerical data are presented using the median and interquartile range (IQR) because the data distribution was not normal.

\section{Ethical aspects}

The research proposal received ethical clearance from the Medical Research Ethics Review Boards at the sites. All the data were anonymized, and the raw data is stored in password-protected electronic files.

\section{Results}

\section{Characteristics of the decedents}

In total, 1625 cases were collected from 9 hospitals and one funeral home. Fifty-four cases were then excluded because their medical records could not be accessed until the end of the data 
Table 1 Institutions of origin

\begin{tabular}{ll}
\hline Institution & Percentage (\%) \\
\hline Sentra Medika Funeral Home, Cibinong & 26.3 \\
Fatmawati General Hospital, Jakarta & 18.2 \\
Persahabatan General Hospital, Jakarta & 16.7 \\
Dr. Cipto Mangunkusumo General Hospital, Jakarta & 12.2 \\
Dr. Hasan Sadikin General Hospital, Bandung & 6,7 \\
R. Said Sukanto Police General Hospital, Jakarta & 6.0 \\
Abdoel Wahab Sjahranie General Hospital, & 5,9 \\
$\quad$ Samarinda & 4,2 \\
Dr. M. Djamil General Hospital, Padang & 1.9 \\
Dr. Soeradji Tirtonegoro General Hospital, Klaten & 1.8 \\
Siloam Hospital Mampang, Jakarta &
\end{tabular}

collection period. Data from the 1571 remaining cases were then analyzed.

\section{Institution}

The institutions where the dead bodies were managed are shown in Table 1.

\section{Gender and age}

The majority of the cases were male $(59.8 \%)$. The median age of the cases was 57 years (interquartile range $=43-66$ ), with the youngest being a neonate and the oldest 113 years old. The age distribution is skewed to the right (Fig. 1). The largest age group is $40-55$ years, while the smallest group is aged 6-10 years.

\section{Religion}

The distribution of the decedents' religion is shown in Fig. 2.

\section{In-patient status}

The majority (98.0\%) of the cases were in-patients, and the rest came from outside the institution. The distribution of the type of treatment ward is indicated in Fig. 3.

\section{COVID-19 infection status at the time of death}

Based on the status of COVID-19 infection at death, only $14.19 \%$ are confirmed positive from the polymerase chain reaction (PCR) examination, as shown in Fig. 4. "Rapid test" was the term commonly used to refer to SARS-CoV-2 antibody test, which was widely used in Indonesia as a screening tool in the early days of the pandemic.

\section{Comorbidity}

Almost half of the cases $(46.4 \%)$ had known comorbidities, while the rest did not have comorbidities $(8.1 \%)$ or were not known to have any $(45.5 \%)$.

Fig. 1 Age distribution

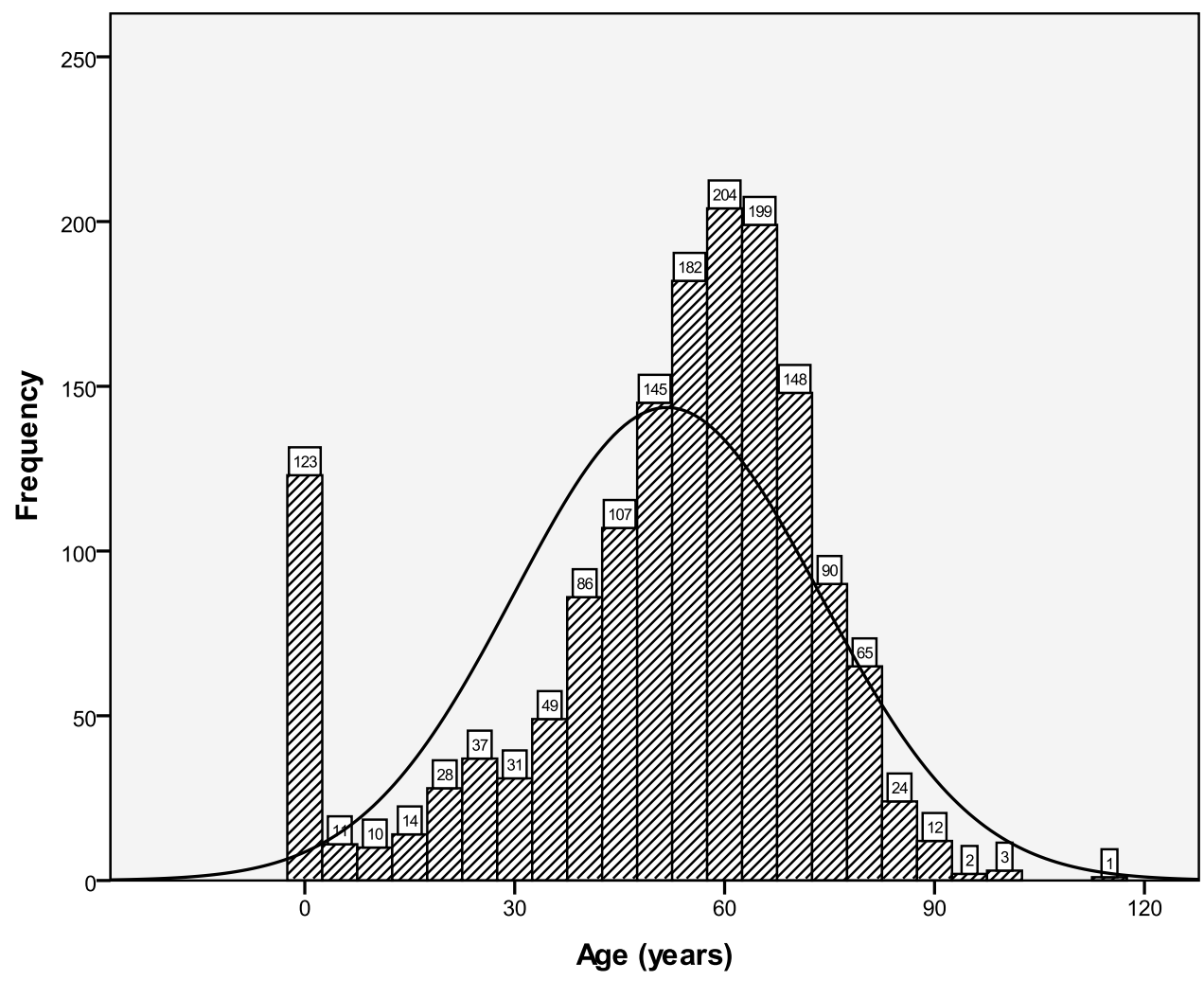


Fig. 2 Distribution of religion

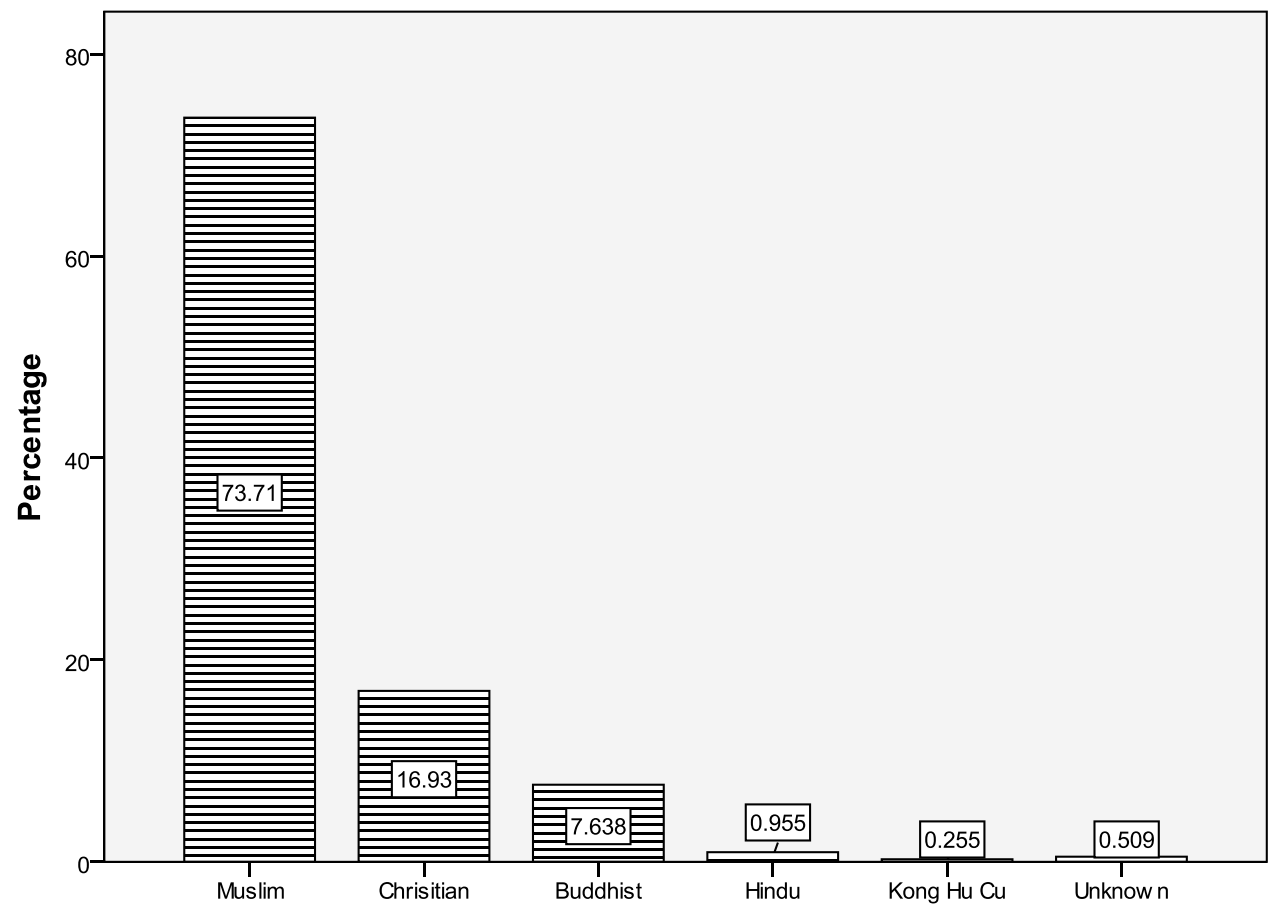

\section{Compliance with management of the dead protocol and funeral arrangements}

In $95.5 \%$ of the cases, the body was treated according to the complete COVID-19 protocol. However, not all of them were buried in COVID-only cemeteries that are specifically allocated by the government (Fig. 5).

\section{The quality of death certificates in deaths due to/ with COVID-19}

Data are collected from 1044 death certificates from 7 hospitals, as shown in Table 2 .

For each element in the death certificate, the level of completeness is shown in Table 3 .

Fig. 3 Distribution of ward type

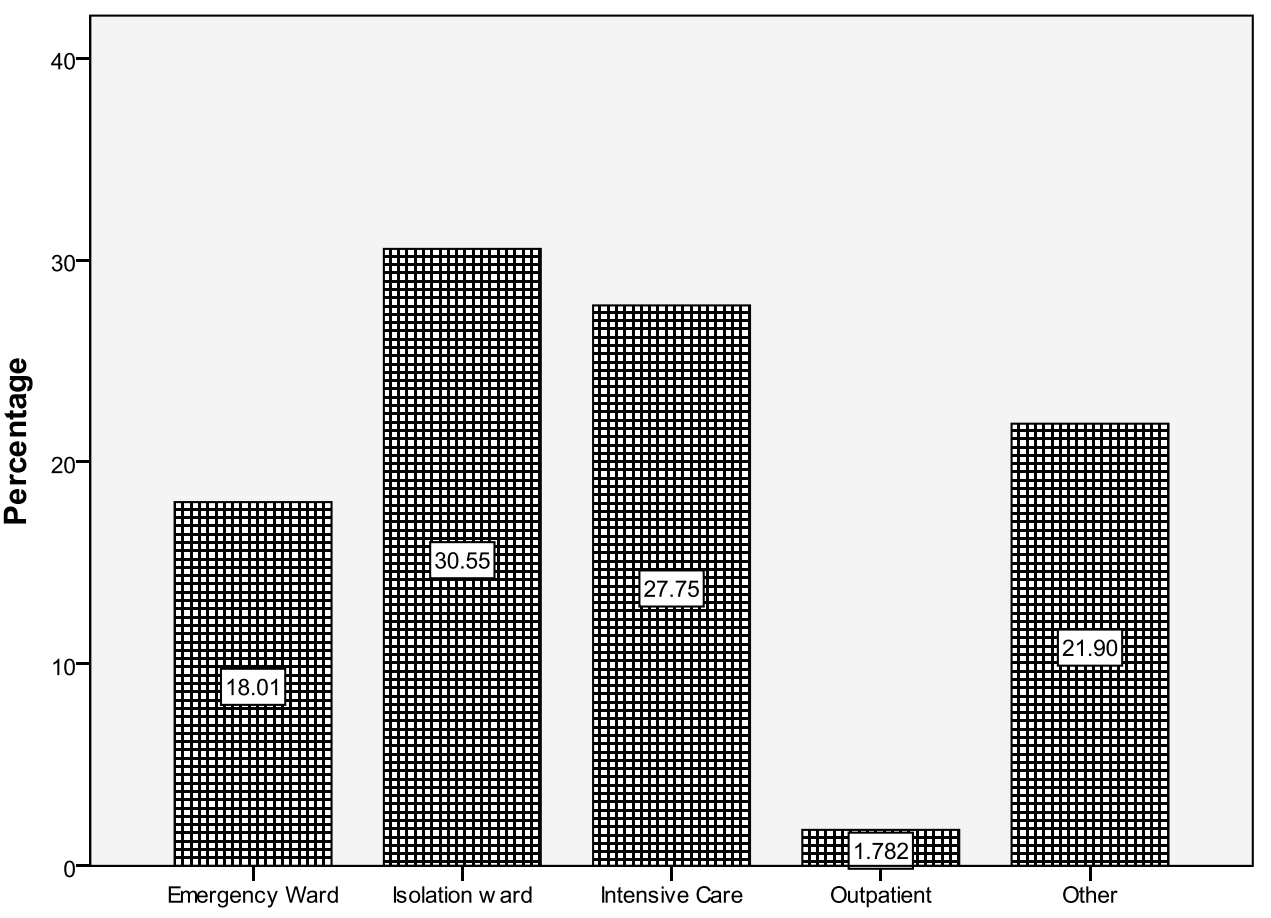




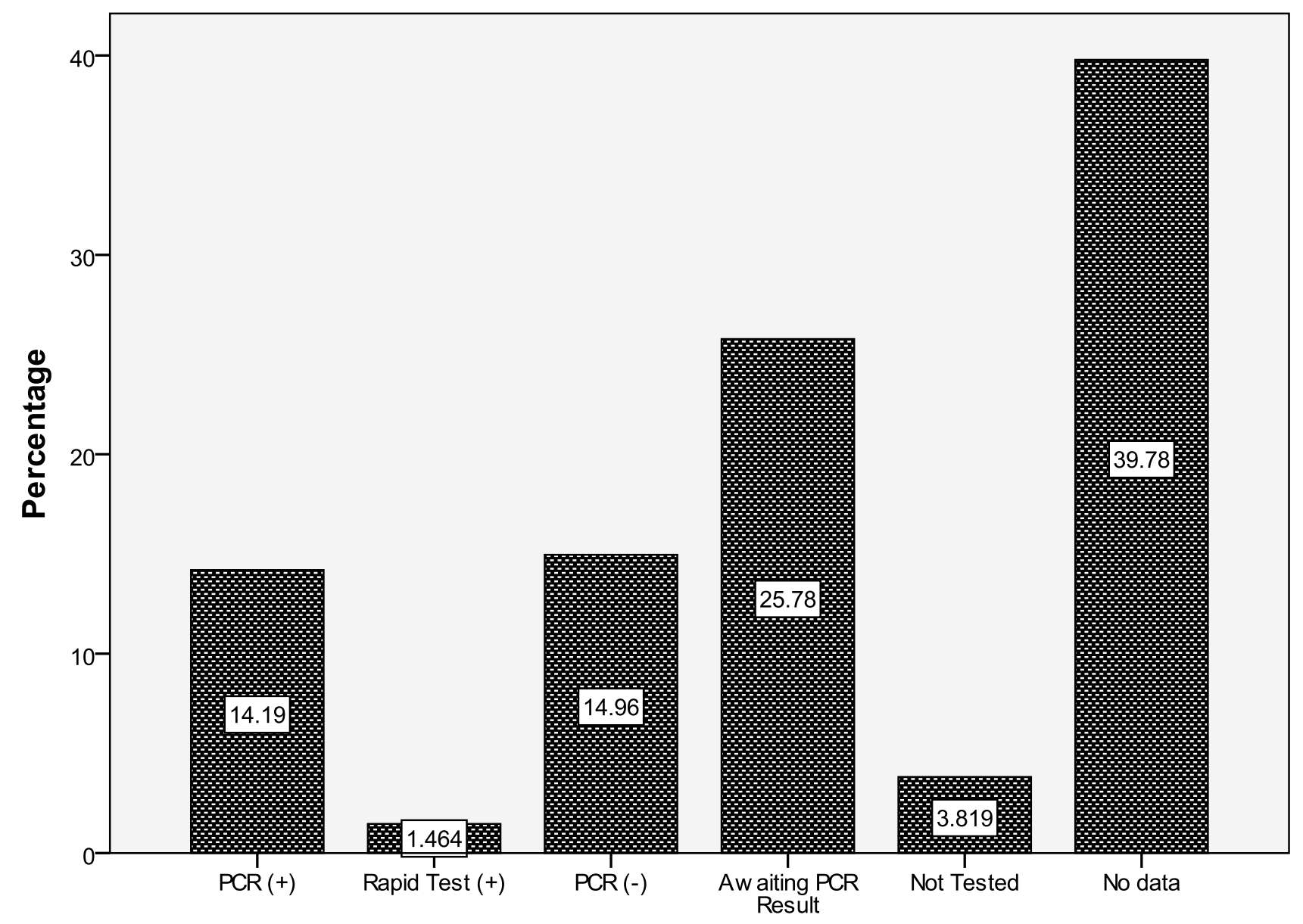

Fig. 4 Status of COVID-19 infection at the time of death

Fig. 5 Distribution of burial sites

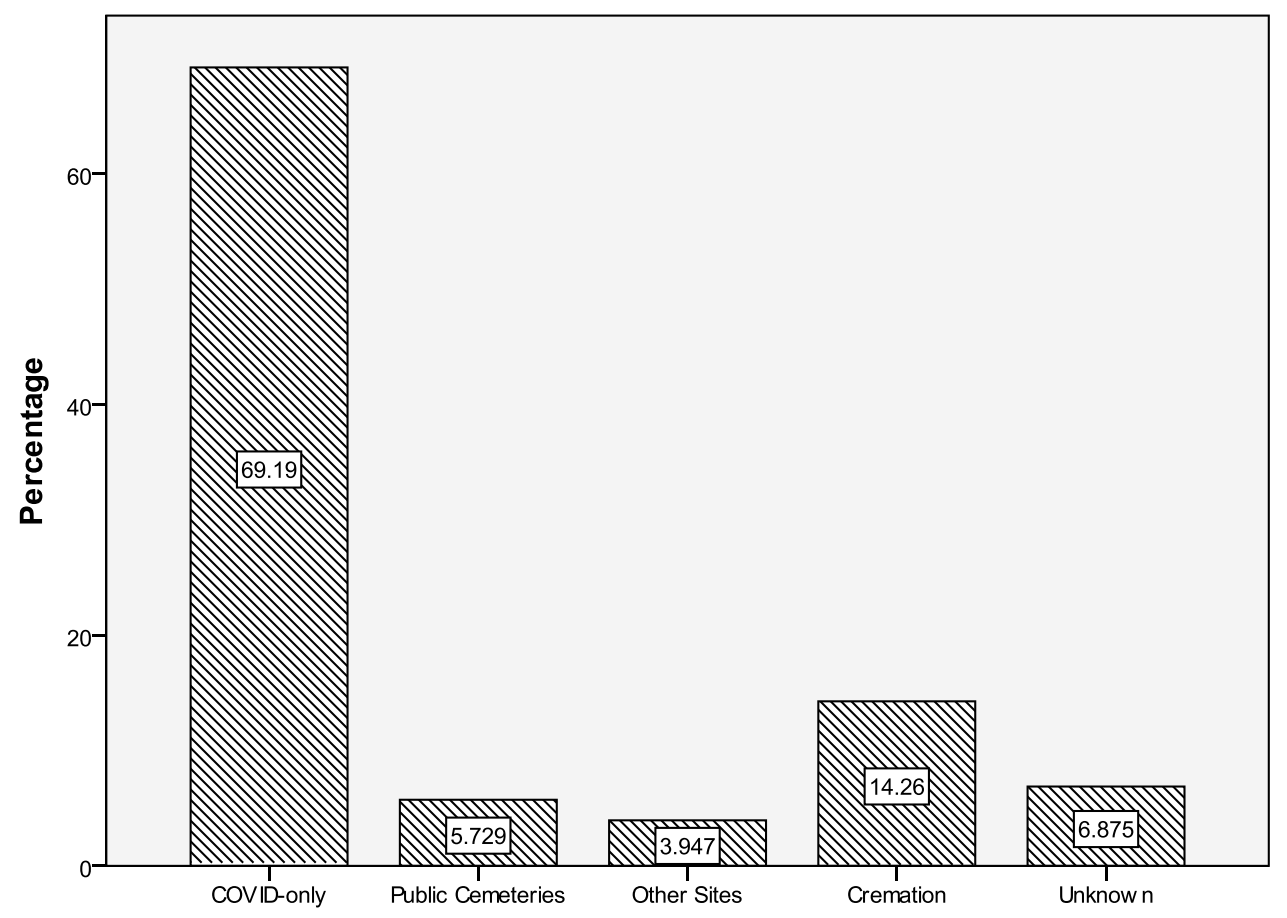


Table 2 Data source of death certificates

\begin{tabular}{ll}
\hline Hospital & Percentage (\%) \\
\hline Fatmawati General Hospital, Jakarta & 27.4 \\
Persahabatan General Hospital, Jakarta & 25.7 \\
Dr. Cipto Mangunkusumo General Hospital, Jakarta & 18.3 \\
Dr. M. Djamil General Hospital, Padang & 11.5 \\
R. Said Sukanto Police General Hospital, Jakarta & 9.0 \\
Abdoel Wahab Sjahranie General Hospital, Sama- & 6.1 \\
$\quad$ rinda & \\
Dr. Soeradji Tirtonegoro General Hospital, Klaten & 2.0 \\
\hline
\end{tabular}

More than $60 \%$ of death certificates did not record "COVID-19" as a cause of death (COD), neither in part I nor part II, while about 3\% listed COVID-19 as more than one level of COD (e.g., immediate and intermediate, or immediate and underlying, or intermediate and underlying cause of death) (Fig. 6). There are variations of writing related to the diagnosis of COVID-19, such as "suspected COVID-19", “COVID-19”, “pneumonia COVID-19”, “viral pneumonia (COVID)", “probable COVID-19”, "COVID-19 suspected pneumonia", "confirmed COVID-19", "COVID-19 due to pneumonia", "COVID-19 due to viral pneumonia", and "COVID-19 (positive rapid test)". Some terms were only used in Indonesia at the beginning of the pandemic, i.e., "person under surveillance" and "patient under observation," that were combined with various diagnoses as mentioned above, e.g., "pneumonia COVID-19 in patient under observation."

Some of the problems related to the causes of death listed in the death certificates that were often encountered are as follows:

- the underlying cause of death was not recorded,

- more than one condition/disease were listed as the underlying cause of death in one case (for example, "type 2

Table 3 Level of completeness of elements in the death certificate

\begin{tabular}{|c|c|c|c|c|}
\hline Variable & $\begin{array}{l}\text { Not filled } \\
(\%)\end{array}$ & $\begin{array}{l}\text { Filled, but incomplete/ } \\
\text { wrong }(\%)\end{array}$ & $\begin{array}{l}\text { Filled completely/ } \\
\text { correctly }(\%)\end{array}$ & Not applicable (\%) \\
\hline Full name & 0.5 & 0.0 & 99.5 & 0.0 \\
\hline Citizen identification number & 33.3 & 0.0 & 64.6 & 2.1 \\
\hline Gender & 2.9 & 1,2 & 95.9 & 0.0 \\
\hline Date of birth & 1,1 & 7.9 & 89.0 & 2.0 \\
\hline Religion & 2,2 & 0.1 & 95.7 & 2.0 \\
\hline Address & 1.4 & 23.6 & 75.0 & 0.0 \\
\hline Marital status & 17.8 & 1.0 & 79.2 & 2.0 \\
\hline Relationship with head of household & 35.3 & 3.5 & 59.1 & 2.0 \\
\hline Time of death & 1.0 & 0.4 & 98.7 & 0.0 \\
\hline Age at death & 16.1 & 0.9 & 83.0 & 0.0 \\
\hline Place of death & 10.2 & 0.0 & 89.8 & 0.0 \\
\hline Basis of diagnosis & 21.6 & 16.7 & 59.7 & 2.0 \\
\hline Cause of death category & 9.7 & 9.8 & 72.7 & 7.9 \\
\hline Certificate completion date (sheet 1 ) & 3,6 & 0.2 & 96.2 & 0.0 \\
\hline Full name of certifying doctor (sheet 1 ) & 3,6 & 0.2 & 96.2 & 0.0 \\
\hline Certifying doctor's signature (sheet 1) & 1.4 & 0.0 & 98.6 & 0.0 \\
\hline Doctor's position \& agency stamp (sheet 1 ) & 47.0 & 2,2 & 50.8 & 0.0 \\
\hline Full name of receiver & 11.8 & 0.9 & 85.3 & 2.0 \\
\hline Relationship with decedent & 37.4 & 1.8 & 58.5 & 2.3 \\
\hline Direct cause of death (a) & 54.9 & 2.9 & 42.0 & 0.2 \\
\hline Intermediate cause of death (b, c) & 9.8 & 15.5 & 27.8 & 46.9 \\
\hline Underlying cause of death (d) & 9.3 & 7,2 & 35.1 & 48.5 \\
\hline $\begin{array}{l}\text { Other conditions that contribute to but are not } \\
\text { related to a-d }\end{array}$ & 41.5 & 1,1 & 10.6 & 46.8 \\
\hline Time-lapse from disease until death & 97.8 & 0.1 & 2.1 & 0.0 \\
\hline ICD-10 coding & 84.8 & 7.0 & 8.2 & 0.0 \\
\hline Certificate completion date (sheet 2 ) & 48.9 & 0.0 & 51.1 & 0.0 \\
\hline Full name of the certifying doctor (sheet 2) & 44.1 & 0.0 & 55.9 & 0.0 \\
\hline Certifying doctor's signature (sheet 2) & 40.7 & 0.0 & 56.6 & 0.0 \\
\hline Doctor's position \& agency stamp (sheet 2) & 83.2 & 0.0 & 16.8 & 0.0 \\
\hline
\end{tabular}




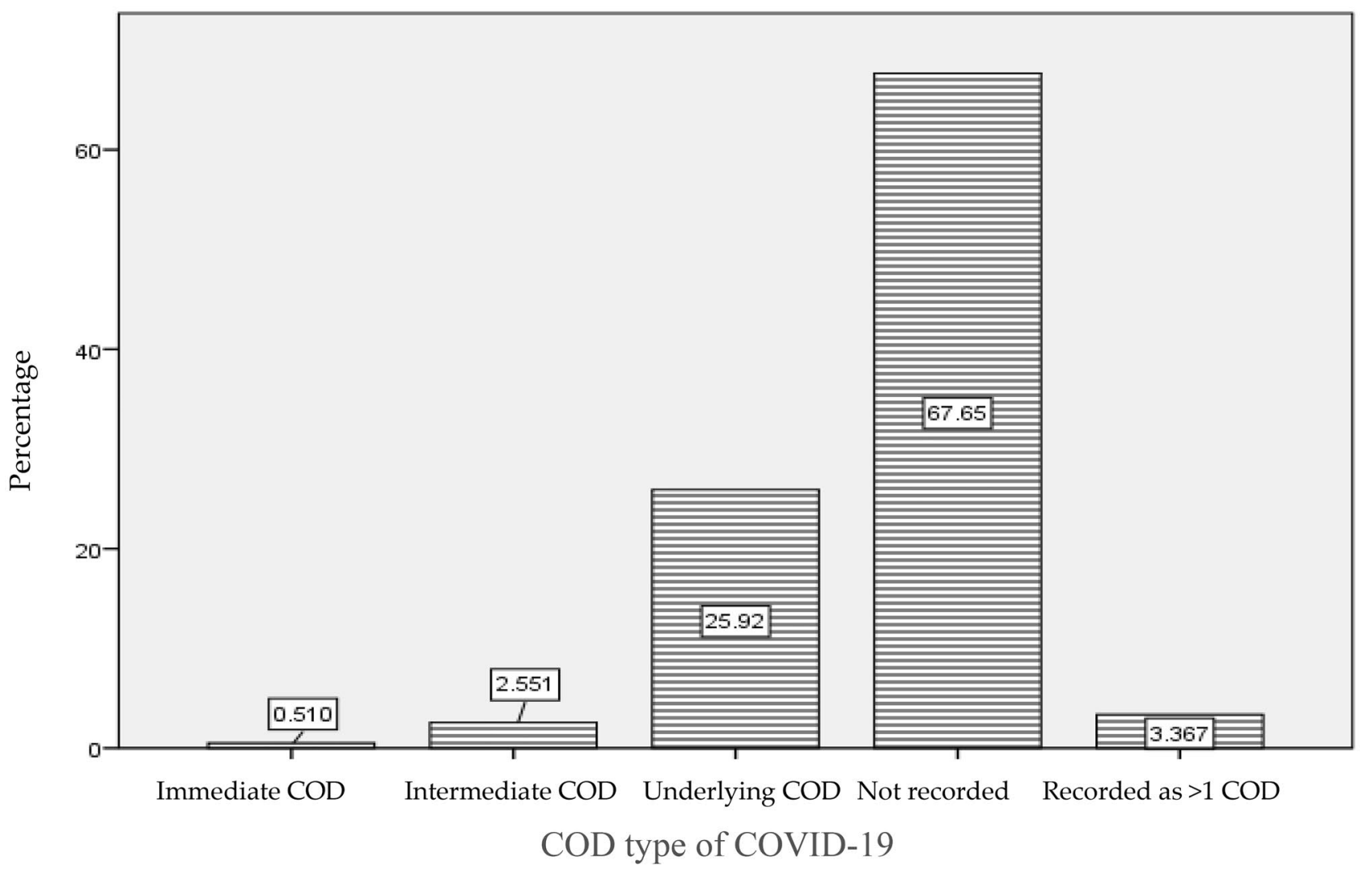

Fig. 6 COVID-19 recorded as cause of death (COD) in part I of the death certificate

diabetes mellitus" and "pneumonia" and "hypertension", "COVID infection" and "ARDS", and "AKI DD/acute on CKD, patient under observation, malnutrition"),

- the sequence of the causes of death was incorrect (for example, "COVID" is listed as an intermediate cause while "asphyxia", which can be caused by COVID, is listed as the underlying cause),

- there was no logical chain of events between the causes of death listed (e.g., "respiratory failure type 2" (direct cause) - "ovarian cancer, end-stage tumor" (intermediate causes) - "pneumonia in patient under observation" (underlying cause) and "aspiration" (direct cause) — "COVID, SIDA, pulmonary TB" (intermediate cause) - "asphyxia" (underlying cause)),

- the terms used were non-standard, unusual, a mix of Indonesian, English, and medical terms, or were not present in the ICD-X list (e.g., "end-stage tumor," "history of DM ketosis," "COVID-19 (positive rapid test)," "high blood pressure in ...?," and "edem pulmoner"),

- The spelling used varied and was not standard (e.g., "irreversible sepsis," "ireversibel sepsis," "ireversible sepsis" and "pnemoni," "pneumonia," "pneumonia").

\section{Discussion}

The population of this study consists of all dead bodies that were managed according to protocols for the management of dead bodies with COVID-19 in Indonesia [6, 11]. According to the protocol, all deaths with a clinical status of confirmed, probable, as well as suspected cases of COVID-19 were managed as COVID-19 deaths. This protocol also includes deadon-arrival (DOA) cases and stillborn fetuses of mothers with confirmed COVID-19. Sometimes a more prudent approach was chosen, and some decedents were managed according to the COVID-19 protocols even if they did not strictly fall into the "probable/confirmed" category, especially in the early days of the pandemic. For example, if there was even the slightest suspicion of COVID-19 (a "suspect" COVID-19 patient) or if no clear history (clinical/contact/travel) could be obtained, e.g., in DOA cases. Thus, for data collection purposes, we included all cases that were managed according to the COVID-19 protocols, even if there was no clear diagnosis of COVID-19 and even if "COVID-19" was not recorded on the death certificate. Using the above criteria, we managed to collect data from 1571 decedents from 9 hospitals and 1 
funeral home from several cities in Indonesia. The first part of the paper discusses the characteristics of those 1571 cases.

In Indonesia, the death certification system is not yet well established. Although there is a standard death certification form issued by the government (which follows the International Form of Medical Certificate of Cause of Death [7]), it is not yet uniformly used in all healthcare facilities. That is why we only managed to collect data of 1044 death certificates from 7 hospitals. The remaining 527 cases come from the 2 hospitals and the funeral home that do not use the standard death certification form (yet), and thus have been excluded from the second part of the paper.

In short, the 1571 cases described in the first part consist of deaths of suspected, probable, and confirmed COVID-19 cases. Of those 1571 cases, only 1044 had a death certificate which follows the standard form, that were then discussed in the second part of the paper.

\section{Characteristics of decedents}

There are 1571 datasets of decedents with COVID-19 in this study, which represent $7.8 \%$ of all deaths due to COVID-19 in Indonesia at the time of writing. Most of the hospitals that participated in this study were located on the island of Java and one each on the islands of Sumatra and Kaliman$\tan$. Unfortunately, there are no data from other islands in Indonesia.

The age distribution appears to be skewed to the right, which shows that death in COVID-19 cases tends to occur at an older age. This distribution is consistent with the results of a study in Wuhan, where COVID-19 patients with severe symptoms had a median age of 64 years [12]. Other studies from China and Indonesia also found that age remains a significant risk factor for death among geriatric patients of all ages [12-14]. A study in Italy also concluded that most patients with COVID-19 who died were men with an average age of 80 years [15]. The role of gender is still controversial because some studies show that males are more prevalent in the severe disease group $[15,16]$. However, some studies do not find any significant differences between the two genders $[12,17]$.

The majority of cases were Muslims and Christians. This distribution is in accordance with the proportion of religious followers in Indonesia. Every religion in Indonesia has published guides for managing dead bodies in line with the COVID-19 protocol [18-22]. The existence of these guidelines assists in the implementation of health protocols in managing dead bodies so that it is not only safe from a medical and public health perspective but also considers religious provisions and the need for bereavement services for the family and relatives to increase compliance to the protocol.
Most cases came from post-in-patient treatment, and most of them were treated in ordinary isolation wards $( \pm 31 \%)$ and intensive care wards $( \pm 28 \%)$. This distribution reflects the availability of intensive rooms, which are more limited in Indonesia in handling severe confirmed cases. At the time of their death, most patients had been tested using PCR, but the results were not yet available. At the time of data collection, only a couple of government-appointed laboratories could perform RT-PCR examinations. The examination itself was also expensive and time-consuming (results were usually sent back to the hospital in 5-7 days' time). As shown in Fig. 4, only about $25 \%$ of cases are still awaiting their PCR results at the time of death. So, the result of those $25 \%$ of cases could theoretically be checked retrospectively in their respective medical records. For this study, however, we wanted to focus on whether the PCR status affected the adherence to management of the dead protocols. Thus, we presented the PCR status as is.

Nearly half of the cases had comorbidities. This is in line with a study in Italy, where as many as $40 \%$ of COVID19 patients who died had comorbidities [15]. Other studies on the relationship between comorbidities and mortality or disease severity in COVID-19 patients in China of all ages show mixed results. In a study conducted in Wuhan, no significant differences in the proportion of patients with hypertension, diabetes, and coronary heart disease were observed between severe and non-severe patients [12]. In contrast, a significant difference was observed between the 54 who died and 137 survivors by another study [16].

Most cases were handled according to the complete protocol for management of the dead with COVID-19 regardless of infection status at death (suspected/probable/confirmed). This fact is per the most current guidelines from the Ministry of Health that recommend that not only bodies with confirmed COVID-19 status are handled according to protocol but also those with probable and even suspected status [6]. A further investigation into the management of the dead that did not follow the complete protocol is needed, especially regarding the obstacles/constraints and strategies to overcome them. Most cases were also buried in COVIDonly cemeteries specially designated by the government Those cemeteries are normally located in the outskirts of the city or in the sub-urban areas. They also conform to the technical specifications of safe burial places, such as the minimum size and depth of the graves, as well as the minimum distance from ground water sources and dwelling places. The use of those specially designated cemeteries is not mandatory but serves to anticipate rejections of the body of COVID-19 deaths from the local community, as frequently happened in the early days of the pandemic, and burials in non-standard burial grounds (e.g., family-owned land). Continuous education to the public is needed about 
the importance of special management of the dead procedures for COVID-19 deaths, so that they are safe for burial.

\section{Quality of death certificates}

There are two essential elements of a death certificate, i.e., administrative elements and the causes of death. The completeness and accuracy of filling in administrative elements will impact the medicolegal aspects of a death certificate. Furthermore, filling in the right causes of death has an essential role in accurate planning actions in overcoming medical and health problems, especially during a pandemic that requires speed of action. Writing the accurate causes of death, especially the underlying cause of death, has a wide range of benefits, both for medical and public health purposes.

In Indonesia, death certificates are issued by the attending physicians (i.e., pulmonologists, internists, intensivists, obstetricians, pediatricians). However, forensic medical specialists usually provide some form of guidance (e.g., inhouse trainings, audit) in filling-out death certificates. As there was much confusion about the pathophysiology and guidelines on how to fill out death certificates of COVID-19 deaths were constantly changing during the early days of the pandemic, the government (i.e., the Ministry of Health) provided a national workshop in October 2020. But because in this study data collection occurred from April until December 2020, the data might have captured the initial confusion and inconsistencies.

Most of the elements in the death certificates of this study were generally filled. However, some elements are often not filled in at all or filled in incompletely/inaccurately. Incompleteness or inaccuracy of administrative elements, such as "citizen identification number," "job position and stamp of the certifying doctor," and "the recipient's relationship with the deceased," can cause problems in terms of civil registration and thus needs to be addressed. Furthermore, if the position and the stamp of the certifying doctor's agency are incomplete, it can be difficult to trace the certifying doctor if there are issues to be confirmed. In Indonesia, most people only use their first names, so they can be confused, especially if the names are common. It is equally important to include data on the relationship between the recipient of the death certificate and the decedent. Apart from providing evidence that those who receive the death certificate are indeed entitled (heir or immediate family), this data can help if there is a need to contact the heir/family later.

Many medical data elements were not filled in or filled in incompletely/inaccurately, including elements of the cause of death. We did indeed find that $60 \%$ of the 1044 death certificates did not record COVID-19 as a cause of death (COD) at all. This finding might be explained by the novelty of COVID-19; much is still unknown about the disease entity and the pathophysiology of the conditions which can lead to death. Furthermore, there were also uncertainties in diagnosing COVID-19, especially in the early days of the pandemic. According to the operational definitions in the Guidelines for Prevention and Control of COVID-19 issued by the Indonesian Ministry of Health [6] to be classified as a "suspected" or "probable" case of COVID-19, a clinical diagnosis (based on clinical symptoms and signs, with or without a close contact to a confirmed case or a history of travel from affected regions) is enough. RT-PCR results are only necessary to establish a diagnosis of "confirmed" cases. In deaths of suspected and probable cases, "COVID19 " was therefore often not explicitly recorded on the death certificates. This confusion/ambiguity can also be seen from the variety of terms used for the inclusion of COVID-19 as a cause of death. In addition, there are inconsistencies in determining the type of cause of death related to COVID19 and its relation to other conditions that are thought to be/ contributed to the cause of death.

The lack of completeness in filling in the elements of the cause of death related to COVID-19 indicates a problem faced by doctors in analyzing cases, especially in the early days of the pandemic when knowledge of pathophysiology and diagnostic criteria were still undergoing very dynamic changes. The operational definition of the criteria for COVID-19 cases in Indonesia itself has changed several times in line with five changes to the interim guidelines for the prevention and control of COVID-19 published in 2020. If these guidelines are not widely disseminated and carefully studied, it can cause confusion and inconsistencies in filling out medical records and death certificates. For example, in the first to fourth versions of the guideline, some terms are used with the definitions that change almost every time the guideline changes. The terminologies used in the first until third versions are "Pasien dalam Pengawasan/PDP (Patient-under-Observation)," "Orang dalam Pemantauan/ODP (Person-under-Surveillance)," Probable Case, and Confirmed Case [23-25]. In the fourth version, a new terminology appeared, namely "Orang Tanpa Gejalal OTG (Asymptomatic Person)" [26]. In the fifth version, the guideline finally followed the World Health Organization standard by using the terminology Suspect, Probable Case, and Confirmed Case [6].

In Indonesia, the death certification system is not yet well established. Although there is a standard death certification form issued by the government (which follows the International Form of Medical Certificate of Cause of Death from the WHO), it is not yet uniformly used in all healthcare facilities. Although "COVID-19" might be entered in both parts I and II of the death certificate, in this study we focused on part I for the following reasons: 
- During the data collection period, not much was known about the pathophysiology of death due to COVID-19. So, most of the time if someone contracted COVID-19 and then died, they were almost automatically thought of to have died due to COVID-19. In other words, deaths with COVID-19 and deaths due to COVID-19 were considered synonymous. Thus, in the study sample "COVID19" was never documented in part II.

- Because the site hospitals were designated COVID-19 referral hospitals, almost all deaths were considered as deaths due to COVID-19, with varying infection status (ranging from suspected to PCR-confirmed cases). At that time, no cases were treated in the hospitals where COVID-19 was considered as a comorbidity or even a coincidental diagnosis, which would render it as a condition to be entered in part II.

- Previous studies conducted in the site hospitals showed that there is still much confusion about what and how to enter in both parts, even in pre-pandemic times. The confusion was even more apparent during the early days of the pandemic and attending physicians mostly concentrated on documenting "COVID-19" in part I.

In most death certificates, the time interval between each cause of death and the time of death was not filled. This finding is unfortunate because determining the time interval from the occurrence of illness to death can help determine the causes of death and sort them into the correct sequence of the underlying, intermediate, and direct causes of death. Writing the time sequence can help the doctor's cognitive process while filling in the causes of death and prevent the confusion of writing for each type of cause of death. In short, the underlying cause of death must occur earlier than/precede the intermediate and direct causes of death. Therefore, for a condition to be chosen as the underlying cause of death, it must have the longest interval from the onset of the disease until the time of death.

There also seems to be some confusion in determining what disease/condition can be determined as a/the cause of death and in determining which disease/condition belongs to which type of cause of death (i.e., whether the cause of death is direct, intermediate, or underlying cause of death). In more than $80 \%$ of certificates, there is a discrepancy or mismatch between the three types of causes of death. This error is classified as major because it can affect the accurate coding of the underlying cause of death [27]. All types of major errors were found in this study, including not writing down the medically acceptable causes of death, writing several competing underlying causes of death, direct, intermediate, and underlying causes of death written in the wrong order, and only writing the direct causes of death without writing the underlying cause of death [28].
The COVID-19 pandemic has presented a challenge to the achievement of national and international health indicator targets. During this pandemic, it is evident that good mortality statistics are needed for monitoring the health status of the population by directly measuring the mortality rate and analyzing the causes and characteristics of death $[29,30]$. Like many countries in Africa and Asia, Indonesia is one of the countries that does not provide death statistics reports as requested by the WHO and the United Nations $[29,31]$. This pandemic has forced all countries to count and report it to the public every day because it is essential in influencing health policy interventions that must be carried out as soon as possible.

Indonesia is an archipelago that consists of more than 17,000 islands. About $60 \%$ of Indonesia's population, lives on Java and Sumatra, the two most populous islands. That might be one of the reasons why previous, pre-pandemic, studies regarding the quality of death certification were mostly conducted in hospitals located in those islands [14, 32]. However, because the pandemic affects not only people living in those two islands, but also everyone in Indonesia (and the rest of the world), it was important to include data from other islands as well. Differentiating deaths as related or unrelated to COVID-19 has become a critical issue because it has a tremendous impact on lives, health, economics, and even politics [30].

\section{Study strengths and weaknesses}

This study is the first multicenter study regarding the characteristics of the decedents handled according to the management of the dead protocol with COVID-19 and the quality of their death certificates in Indonesia. Data were obtained from several hospitals in Java, Sumatra, and Kalimantan, where there are forensic medical specialists so that they may not fully represent conditions in other areas in Indonesia, especially in places that are not handled by forensics medical specialists. In addition, this study has a cross-sectional design so that it only describes a momentary condition. Another drawback of this study is that in some cases data could only be collected from the death certificates as is and could not be confirmed by/compared with data in their respective medical records although the medical records themselves could be accessed. Thus, an analysis of the accuracy of diagnosis/choice of the cause of death cannot be carried out based on the actual medical data, as documented in the complete medical record.

There is also no data from direct post-mortem examinations (autopsies) because, at the time of data collection, no autopsies were carried out in Indonesia on dead bodies suspected of having died due to COVID-19. In the Guidelines for Prevention and Control of COVID-19 issued by the Indonesian Ministry of Health [6], COVID-19 can be 
established as the cause of death based on a clinical diagnosis (i.e., clinical symptoms and signs that are consistent with a fatal disease course in "suspected/probable/confirmed" COVID-19 cases. Furthermore, for surveillance purposes, a "COVID-19 death" is defined as "any death of a person with probable/confirmed COVID-19" [6]. In other words, it is enough to establish a clinical (antemortem) diagnosis of "COVID-19" and a complete post-mortem examination of the body is not necessary to analyze and confirm the actual cause of death. Therefore, the lack of post-mortem confirmation is a major hindrance in obtaining an accurate number of true COVID-19 deaths (i.e., deaths due to COVID-19 and not just deaths with COVID-19) and can lead to the inflation of the number of COVID-19 deaths, as not everyone with COVID-19 actually dies from it.

Despite the abovementioned shortcomings, this study has several strengths. First, the sample size was quite large and was obtained from various referral hospitals. As referral hospitals, those hospitals handle the majority of COVID19 cases in their surrounding area. Thus, it is hoped that the results obtained will adequately provide an overview of the real-life conditions. Second, the research variables studied were also quite numerous so that discussions could be carried out in more depth. Furthermore, the analysis was carried out not only on the completeness of the death certificates but also on the accuracy of the elements and the consistency between elements (that is, between the three types of causes of death) so that it can be used to improve cause of death certification in Indonesia, including in deaths due to/with COVID-19.

We believe that this study might benefit an international readership. Although this study was conducted in Indonesia, the problem of inaccurate death certification is also commonly found in other countries/regions. In addition to being an issue that is often dismissed as trivial by the medical community in general, death certification is also frequently thought of as a nuisance. This is even more apparent during the COVID-19 pandemic, where clinicians were often already overwhelmed by the volume of cases that they rarely thought about the implications of an inaccurate death certificate. By studying the severity of this problem, we hope to increase awareness and advocate for the appropriate policies.

\section{Conclusion}

The characteristics of the decedents managed according to the COVID-19 management of the dead protocol vary and represent a snapshot of the Indonesian situation during the first months of the pandemic. It is hoped that the results of the analysis on the quality of the death certificates can be used to improve the national system for recording causes of death, especially with regard to COVID-19.

\section{Key points}

1. The COVID-19 pandemic has significantly impacted the management of dead bodies.

2. Protocols for managing dead bodies with COVID-19 have been implemented in Indonesia based on international guidelines.

3. The demographic characteristic of decedents with COVID-19 are consistent with those of the Indonesian population in general.

4. Most cases were managed compliant with the standard protocol regardless of their COVID-19 infection status known at the time of death.

5. The quality of death certificates of COVID-19 deaths needs to be improved.

Acknowledgements This study was supported by the directors of the hospitals/sites, the head of R. S. Sukanto Police Hospital, Jakarta and the director of Sentra Medika Funeral Home, Cibinong. Data collection was aided by Andrew Rens Salendu, Farah Kaurow, Ari Sri Wulandari, and Karen Esrella. We would also like to thank Lipur Riyantiningtyas, Kunthi Yulianti, Naomi Yosiati, C. Andryani, and Aberta Karolina for their contribution in the conception of this study.

Author contribution All the authors contributed to the study conception and design. Data acquisition and initial analysis were performed by PDIM, CM, Y, RS, BIF, AAM, KS, and EU. Final analysis was performed by PDIM, CM, Y, RS, AAM, KS, and YFS. The first draft of the manuscript was written by CM, Y, RS, AAM, KS, EU, YFS. The draft was revised critically by PDIM, BIF, and MZSH. All the authors commented on the draft of the manuscript and have read and approved the final version.

\section{Declarations}

Ethics approval The research proposal received ethical clearance from the Medical Research Ethics Review Boards at the hospitals/sites.

\section{References}

1. Samarji A. Overloaded morgues, mass graves and infectious remains: how forensic pathologists handle the coronavirus dead. The Conversation. 2020;1-7. https://theconversation.com/overloaded-morguesmass-graves-and-infectious-remains-how-forensic-pathologists-handlethe-coronavirus-dead-135275. Accessed 13 Apr 2020.

2. O'Keeffe J. Death care during the COVID-19 pandemic: understanding the public health risks. Environ Heal Rev. 2020;63:40-7.

3. McKenzie-Sutter H. "We have no other choice": How funerals are adapting to COVID-19 measures. The Canadian Press. 2020. https://www.ctvnews.ca/health/coronavirus/ 
we-have-no-other-choice-how-funerals-are-adapting-to-covid-19measures-1.4873083. Accessed 23 Dec 2020.

4. WHO Interim Guidance. Infection prevention and control for the safe management of a dead body in the context of COVID-19. J Hosp Infect. 2020;104:246-51.

5. Finegan O, Fonseca S, Guyomarc'h P, Morcillo Mendez MD, Rodriguez Gonzalez J, Tidball-Binz M, et al. International Committee of the Red Cross (ICRC): general guidance for the management of the dead related to COVID-19. Forensic Sci Int Synerg. 2020;2:129-37.

6. Kementerian Kesehatan Republik Indonesia. Guidelines for prevention and control of COVID-19 per July 13, 2020. Kementerian Kesehatan Republik Indonesia. 2020.

7. Medical certification of cause of death; instructions for physicians on use of international form of medical certificate of cause of death. World Health Organization. 1979.

8. World Health Organization (WHO). International guidelines for certification and classification (coding) of COVID-19 as cause of death. 2020.

9. Centers of Disease Control and Prevention (CDC). Guidance for certifying deaths due to coronavirus disease 2019 (COVID-19). 2020.

10. Lund Research. Total population sampling. Laerd Dissertation. 2012. http://dissertation.laerd.com/total-population-sampling.php. Accessed 15 May 2017.

11. Perhimpunan Dokter Forensik Indonesia (PDFI). Guidelines for managing dead bodies with suspected COVID-19. 2020.

12. Zhang J, Dong X, Cao Y, Yuan Y, Yang Y, Yan Y, et al. Clinical characteristics of 140 patients infected with SARS-CoV-2 in Wuhan. China Epidemiol Genet. 2020;75:1730-41.

13. Wu C, Chen X, Cai Y, Xia J, Zhou X, Xu S, Risk factors associated with acute respiratory distress syndrome and death in patients with coronavirus disease, et al. pneumonia in Wuhan. China JAMA. 2019;2020:E1-10.

14. Rozaliyani A, Savitri AI, Setianingrum F, Shelly TN, Ratnasari V, Kuswindarti R, et al. Factors associated with death in COVID-19 patients in Jakarta, Indonesia: an epidemiological study. Acta Med Indones. 2020;52:246-54.

15. SARS-CoV-2 Surveillance Group. Characteristics of SARS$\mathrm{CoV}-2$ patients dying in Italy Report based on available data on November 18th, 2020. 2020. https://www.epicentro.iss.it/en/ coronavirus/bollettino/Report-COVID-2019_21_may_2020.pdf. Accessed 21 May 2020.

16. Zhou F, Yu T, Du R, Fan G, Liu Y, Liu Z, et al. Clinical course and risk factors for mortality of adult inpatients with COVID19 in Wuhan, China: a retrospective cohort study. Lancet. 2020;395:1054-62.

17. Wang D, Hu B, Hu C, Zhu F, Liu X, Zhang J, et al. Clinical characteristics of 138 hospitalized patients with 2019 novel coronavirusinfected pneumonia in Wuhan, China. JAMA. 2020;E1-9.
18. Majelis Ulama Indonesia. Fatwa of the Indonesian Ulema Council No. 18/2020 regarding guidelines for managing corpses (tajhiz al-jana'iz) of Muslims infected with COVID-19. 2020;1-11.

19. Oikumene. Guide to services \& mourning services for church members who are positive for COVID-19. 2020.

20. Parisada Hindu Dharma Indonesia Pusat. Guidelines for the care of corpses and the Pitra Yajna ceremony for the bodies of COVID19 patients. 2020.

21. Kementerian Agama Republik Indonesia. How to pray for the bodies of Buddhists who died of COVID-19. 2020.

22. Kementerian Agama Republik Indonesia. Protocols for handling the bodies of Catholic COVID-19 patients. 2020.

23. Direktorat Jenderal Pencegahan dan Pengendalian Penyakit. Preparedness guidelines for infection with the novel coronavirus (2019-nCoV) as of January 28, 2020. Kementrian Kesehatan Republik Indonesia. 2020;75.

24. Direktorat Jenderal Pencegahan dan Pengendalian Penyakit. Guidelines for preparedness to deal with coronavirus disease (COVID-19) as of February 17, 2020. Kementerian Kesehatan Republik Indonesia. 2020.

25. Direktoral Jenderal Pencegahan dan Pengendalian Penyakit. Guidelines for the prevention and control of coronavirus disease (COVID-19) as of March 16, 2020. Kementerian Kesehatan Republik Indonesia. 2020.

26. Direktoral Jenderal Pencegahan dan Pengendalian Penyakit. Guidelines for the prevention and control of coronavirus disease (COVID-19) as of March 27, 2020. Kementerian Kesehatan Republik Indonesia. 2020.

27. Burger EH, van der Merwe L, Volmink J. Errors in the completion of the death notification form. South African Med J. 2007;97:1077-81.

28. McGivern L, Shulman L, Carney JK, Shapiro S, Bundock E. Death certification errors and the effect on mortality statistics. Public Health Rep. 2017;132:669-75.

29. World Health Organization. Improving mortality statistics through civil registration and vital statistics systems. Technical Meeting, November 4-5, Chateau de Penthes. 2014;4-5.

30. Sorci G, Faivre B, Morand S. Explaining among-country variation in COVID-19 case fatality rate. Sci Rep. 2020;10:1-11.

31. United Nations. Handbook on training in civil registration and vital statistics Systems. New York. 2002.

32. Meilia PDI, Salendu AR. Kualitas Sertifikat Medis Penyebab Kematian (SMPK) di RSUP Persahabatan Tahun 2016-2018. J Indones Forensic Leg Med. 2021;2:132-44.

Publisher's Note Springer Nature remains neutral with regard to jurisdictional claims in published maps and institutional affiliations. 